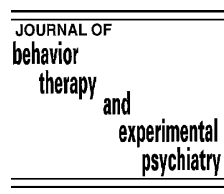

www.elsevier.com/locate/jbtep

\title{
Do children with obesity implicitly identify with sedentariness and fat food?
}

\author{
Mietje Craeynest ${ }^{\mathrm{a}, \mathrm{c}, *}$, Geert Crombez $^{\mathrm{a}, \mathrm{c}}$, Jan De Houwer ${ }^{\mathrm{a}}$, \\ Benedicte Deforche ${ }^{\mathrm{b}, \mathrm{c}}$, Ilse De Bourdeaudhuij ${ }^{\mathrm{b}, \mathrm{c}}$ \\ ${ }^{a}$ Department of Experimental Clinical and Health Psychology, Ghent University, Henri Dunantlaan 2, \\ B-9000 Ghent, Belgium \\ ${ }^{\mathrm{b}}$ Department of Movement and Sports Sciences, Ghent University, Watersportlaan 2, B-9000 Ghent, Belgium \\ ${ }^{\mathrm{c}}$ Research Institute for Psychology and Health, Ghent University, Belgium
}

Received 25 March 2005; received in revised form 2 February 2006; accepted 9 February 2006

\begin{abstract}
We investigated whether youngsters with obesity $(n=39)$ differed from a control group $(n=39)$ in their self-reported attitudes towards and in their implicit identification with physical activity and food. Self-reported attitudes were assessed using a rating scale; implicit identification was assessed using a self-concept Implicit Association Task (IAT). Results revealed a marked group difference on the implicit identification with food: Only youngsters without obesity identified themselves more with non-fat food than with fat food.
\end{abstract}

(C) 2006 Elsevier Ltd. All rights reserved.

Keywords: Obesity; Children; Implicit; Identification; IAT; Food

\section{Introduction}

Obesity has reached epidemic proportions worldwide (James, Leach, Kalamara, \& Shayeghi, 2001; Popkin, 1998). Because obesity develops early on in life and tracks into adulthood (Eriksson, Forsen, Tuomilehto, Osmond, \& Barker, 2001; Togashi et al., 2002), research about the initiation and maintenance of childhood obesity is warranted. There is

\footnotetext{
${ }^{*}$ Corresponding author. Department of Experimental Clinical and Health Psychology, Ghent University, Watersportlaan 2, B-9000 Ghent, Belgium. Tel.: + 3292648636 ; fax: + 3292646484 .

E-mail address: Mietje.Craeynest@UGent.be (M. Craeynest).
} 
accumulating evidence that obesity is caused by an interaction of a genetic predisposition and environmental influences related to dietary factors and a sedentary lifestyle (Morgan, Tanofsky-Kraff, Wilfley, \& Yanovski, 2002). Studies using behavioural indicators revealed that youngsters with obesity have low levels of physical activity (Trost, Sirard, Dowda, Pfeiffer, \& Pate, 2003). Many studies have found that children with obesity consume more fat, sugars and proteins than their lean peers (McGloin et al., 2002; Nicklas, Yang, Baranowski, Zakeri, \& Berenson, 2003).

One of the possible explanations for this behavioural pattern may be their attitudes towards exercise and food: Youngsters with obesity may have more positive attitudes towards fat food and sedentariness than children without obesity. Most studies assessing attitudes have used self-reports, which are considered explicit measures because questions are asked in a direct way (e.g., Brug, Lechner, \& Devries, 1995; Smith \& Biddle, 1999). Some of these studies revealed that children with obesity report a positive attitude towards physical activity (Deforche, De Bourdeaudhuij, Tanghe, Hills, \& De Bode, 2004), and a less positive one towards unhealthy food than controls (Perl, Mandic, Primorac, Klapec, \& Perl, 1998). Although explicit measures are often accurate predictors of eating and exercising, there are several reasons why their predictive and explanatory value may be limited in some situations. First, they are completed with conscious control, and can be influenced by self-presentation and social desirability strategies. Second, according to Fazio (1990), attitudes guide behaviour in two different ways: On the one hand, behaviour can be based primarily on a deliberate and conscious analysis of the costs and benefits of that behaviour. This kind of attitudes is often called 'explicit attitudes' and can be assessed using direct or explicit measures such as self-reports. On the other hand, when there is little motivation or opportunity to engage in controlled processing, attitudes influence behaviour rather automatically. These attitudes are often called 'implicit attitudes'. They are best assessed in an implicit or indirect way, for instance using response time based measures (Fazio \& Olson, 2003).

To assess implicit attitudes, several indirect measures have been developed (Fazio, 2001; Fazio \& Olson, 2003). The most well-known is the Implicit Association Task (IAT), developed by Greenwald, McGhee, and Schwartz (1998). The IAT is a computeradministered sorting task that measures the degree to which an individual associates conceptual categories. Participants are instructed to sort stimuli that belong to one of four categories: two target categories (e.g., flowers and insects) and two attribute categories (e.g., positive and negative nouns). Sorting has to be done as fast and as accurately as possible, by pressing on one of two response keys. Each response key represents one target and one attribute category. The idea underlying the task is that response time should be shorter when the same response is used for an attribute and a target category that are associated in memory (e.g., flowers and positive versus insects and negative) than when the same response is used for two unrelated categories (e.g., flowers and negative versus insects and positive). This pattern of response facilitation is thought to reflect automatic, implicit processing.

An intriguing hypothesis is then that individuals with obesity have more positive implicit attitudes towards fat food than individuals without obesity. However, the available evidence offers little support for this hypothesis. Using the IAT, Roefs and Jansen (2002) found that adults with obesity even had more negative implicit attitudes towards high-fat food than normal-weight controls. Using an Extrinsic Affective Simon Task (EAST; De Houwer, 2003), which is an alternative indirect measure, we also failed to find that obese 
and non-obese children differed primarily with regard to their implicit attitudes towards unhealthy (sugar and fat) food (Craeynest et al., 2005). Instead, our results indicated that children with obesity tended to have a more positive attitude towards both unhealthy and healthy food than the lean control group.

Counterintuitive results with implicit attitude measures are not limited to the domain of obesity. Similar unexpected results have been found in addiction. For instance, Wiers, van Woerden, Smulders, and de Jong (2002); also see De Houwer, Crombez, Koster, and De Beul (2004) found that both light and heavy drinkers showed strong negative implicit attitudes towards alcohol. Likewise, Swanson, Rudman, and Greenwald (2001) reported three experiments that failed to find evidence for positive implicit attitudes towards smoking in smokers. Karpinski and Hilton (2001) argued that such unexpected findings could be due to the fact that implicit measures such as the IAT might register societal instead of personal attitudes. This could distort measures of implicit attitudes towards objects such as fat food, alcohol and smoking, because there are strong societal views about these attitude objects.

In order to minimize the impact of societal views, a self-concept variant of the IAT may be useful. A self-concept IAT is based on Greenwald's et al. (2002) definition that 'the self-concept is the association of the concept of self with one ore more (nonvalence) attribute concepts' (p. 5), and could therefore give an idea of the degree of identification of the participant with those attribute concepts. Swanson et al. (2001) (Experiments 2 and 3) successfully used such variant in the context of smoking, assessing the associations between words referring to self versus other and smoking versus non-smoking pictures in smokers and non-smokers. The results revealed that smokers implicitly identified themselves more with smoking than nonsmokers. That is, smokers but not non-smokers were faster in a task in which they pressed the first key for words referring to the self (e.g., me) and pictures related to smoking (e.g., the picture of a cigarette) and the second key for words referring to others (e.g., them) and pictures unrelated to smoking (e.g., the picture of a pencil). The fact that the expected group difference was found in this IAT suggests that the self-concept variant of the IAT is less sensitive to societal views than the assessment of implicit attitudes in the standard IAT.

The aim of this study was to investigate whether the implicit self-concept is related to fat versus non-fat food, and exercising versus sedentariness in children with and without obesity. Also self-reported attitude measures towards physical activity and food were used. In accordance with health-based societal norms, it was expected that both groups explicitly prefer exercise and non-fat food in comparison to inactivity and fat food. Of particular relevance to this study was the hypothesis that, in comparison with lean children, children with obesity implicitly identify themselves more with sedentary activities and fat food than with exercising and non-fat food.

\section{Method}

\subsection{Participants}

Thirty-nine children and adolescents with severe obesity (mean $\mathrm{ABMI}^{1}=166.70 \%$, $\mathrm{SD}=23.77 ; 16$ boys; age $M=14.12, \mathrm{SD}=2.43$, range $9-18$ years old) were recruited

\footnotetext{
${ }^{1}$ The Body Mass Index (BMI; weight $/$ height $^{2} ; \mathrm{kg} / \mathrm{m}^{2}$ ) is accepted as a reliable and valid index of relative adiposity. However, as mean normal values of BMI vary substantially with age and values for individuals of
} 
during the first week of an inpatient treatment in a Belgian medical-paediatric centre, specialized in the treatment of youth obesity. Thirty-nine youngsters without obesity were recruited in Belgian schools and were matched on gender, age and educational level (mean $\mathrm{ABMI}=103.44 \%, \mathrm{SD}=12.22 ; 17$ boys; age $M=14.00, \mathrm{SD}=2.40$, range 9-18 years old). Both groups did not differ in age, $t<1$, and in sex and educational level, all $\chi^{2}$ s $<1$.

\subsection{Materials}

All participants carried out two IATs: one task was related to physical activity, and one task was related to food. To asses the explicit attitudes, participants were asked to rate the physical activity and food target concepts on two graphic scales.

\subsubsection{Implicit Association Task}

A first task assessed their identification with physical activity versus sedentary activities; in a second task, their identification with fat food versus non-fat food was assessed. In line with Swanson et al., 2001 (Experiments 2 and 3), the attribute stimuli consisted of a set of six words related to the self (e.g., I, me, myself) and six words related to others (e.g., he, she, them). In the physical activity task, targets were six pictures of an exercising child (e.g., running, cycling, playing basket) and six pictures of an inactive child (e.g., sleeping, reading, watching TV). In the food task, targets were six pictures of fat food (e.g., French fries, hamburger, chocolate) and six pictures of non-fat food (e.g., vegetables, fruit, yoghurt). All stimuli are presented in the Appendix.

The IATs were run on an IBM compatible Pentium II laptop with a $15^{\prime \prime}$ colour screen using 1.33 software, which measures reaction times (RTs) with millisecond accuracy (De Clercq, Crombez, Buysse, \& Roeyers, 2003). On each trial, participants were instructed to classify as quickly and as accurately as possible a stimulus word or picture. The category labels 'self', 'other', and respectively 'fat' and 'non-fat' or 'exercising' and 'resting' were presented in the left and right top corner of the screen and remained there throughout each block. Participants responded to the stimuli by pressing either the 'q' key with the left index finger or the ' $m$ ' key with the right index finger on an AZERTY keyboard. Each stimulus was presented in the centre of the screen. Letters were $7 \mathrm{~mm}$ high and $5 \mathrm{~mm}$ wide. Food pictures were $14 \mathrm{~cm} \times 14 \mathrm{~cm}$, physical activity pictures were $19 \mathrm{~cm} \times 14 \mathrm{~cm}$. Pictures were coloured, all words were presented in black, and the background of the screen was white.

\subsubsection{Self-reports}

Participants were asked to indicate on two $164 \mathrm{~cm}$ graphic scales (see Nosek, Banaji, \& Greenwald, 2002; Swanson et al., 2001) how much they liked or disliked the pictures of the target concepts of the physical activity and food IAT. All pictures were $10 \mathrm{~cm} \times 7 \mathrm{~cm}$. Each scale had 20 increments ranging from 0 to 20 . The two extremes were indicated with a schematic frowning face (0) and a schematic smiling face (20). Food and physical activity

\section{(footnote continued)}

different ages are difficult to compare, an adjusted BMI (ABMI) was used. ABMI was calculated using the formula (actual BMI/ideal BMI [50th percentile for same sex and age]) $\times 100$ (Valverde, Patin, Oliveira, Lopez, \& Vitolo, 1998). The 50th percentiles were derived from Flemish growth reference charts. An ABMI of $100 \%$ is considered ideal. 
stimuli had to be rated separately, using the same scale. Pictures had to be ranked with the restriction of a maximum of one picture per increment.

\subsection{Procedure}

The obesity group was tested at the Department of Movement and Sports Sciences at Ghent University. Most of the control children were tested in an available class room of their school, and five of them were tested at home. All of the children were tested individually. The order, in which both IATs were administered, was counterbalanced. Thereafter, pictures were ranked. The order in which the food and physical activity pictures had to be ranked on the scale was counterbalanced too.

Each IAT consisted of seven blocks of trials: (1) a practice block with attribute stimuli only (self vs. other); (2) a practice block with target stimuli only (e.g., non-fat food vs. fat food); (3) a critical combined block with all stimuli (e.g., non-fat food + self vs. fat food + other); (4) repeat of Block 3; (5) a practice block with target stimuli only but with a reversal of the response key assignments; (6) a critical combined block with all stimuli, using the reversed key assignments of Block 5 (e.g., fat food + self vs. non-fat food + other); (7) same as Block 6. The order in which participants performed the mixed categorization blocks (e.g., Blocks 3-4 and 6-7) as well as the key that was assigned to the attribute stimuli (e.g., press 'm' for self vs. press ' $m$ ' for other) was counterbalanced. Each practice block consisted of 24 trials (each attribute or target stimulus twice) and each critical block had 48 trials (each attribute and target stimulus twice). Stimuli were always presented in a random order, whereby the combined blocks did not necessarily alternate between target and attribute stimuli. The inter-trial interval was $400 \mathrm{~ms}$. If the participant responded incorrectly, a red cross appeared for $400 \mathrm{~ms}$ on the screen and the next stimulus was presented.

\section{Results}

\subsection{Implicit Association Task}

IAT scores were calculated using the scoring algorithm proposed by Greenwald, Nosek, and Banaji (2003) but the same effects were found when we analysed the conventional measure (Greenwald et al., 1998). For reasons of clarity, IAT effects are reported in milliseconds (i.e., mean reaction time on self + fat food/resting minus mean reaction time on self + non-fat food/exercising), with negative scores respectively indicating stronger associations between self and activity than between self and resting on the physical activity task, and stronger associations between self and fat food than between self and non-fat food on the food task.

Initial analyses showed that the order in which the two IATs were performed did not have an effect, all $F \mathrm{~s}<2.88$. Also, no effects were found for age, all $F \mathrm{~s}<1$, sex, all $F$ s $<1.05$, and educational level, all $F$ s $<1$. Therefore, we ignored these variables in further analyses and used a Repeated Measures ANOVA with group (obese vs. normalweight participants) and type of IAT (food vs. physical activity) as independent variables, and the D600 IAT scores as dependent variable. Delta $(\delta)$ is reported as an estimate of effect size. A $\delta$ of $0.20,0.50$ and 0.80 was used as a threshold to define small, medium and large effects respectively (Cohen, 1988). 
Table 1

Mean and standardized untransformed IAT sores in ms as a function of group and IAT task in children with and without obesity

\begin{tabular}{|c|c|c|c|c|}
\hline \multirow[t]{2}{*}{ Task } & \multicolumn{2}{|l|}{ Obesity } & \multicolumn{2}{|c|}{ Normal-weight } \\
\hline & $M$ & SD & $M$ & SD \\
\hline Physical activity & -22.42 & 181.71 & -4.58 & 192.25 \\
\hline Food & $-14.02^{\mathrm{a}}$ & 198.32 & $81.07^{\mathrm{a}}$ & 197.01 \\
\hline
\end{tabular}

${ }^{\mathrm{a}}$ Differs significant at the $p<0.05$ level.

The main effect of group was not significant, $F(1,76)=2.32$. However, there was a significant main effect of type of IAT, $F(1,76)=6.32, p=0.05, \delta=0.08$, indicating that the IAT-effect on the food IAT was larger than the effect on the physical activity IAT. More interestingly, also the interaction between group and type of IAT was significant, $F(1,76)=4.82, p<0.05, \delta=0.06$. Post hoc independent t-tests showed that the groups differed on the food IAT but not on the physical activity IAT, respectively $t(76)=2.14$, $p<0.05, \delta=0.11$, and $t(76)=0.64$, ns. Further, one sample $t$-tests on the mean scores on the food IAT showed that the IAT-effect differed significant from zero for the control group, but not for the obesity group, respectively $t(38)=2.75, p<0.01, \delta=0.17$, and $t(38)=0.26$, ns. This indicated that the control group associated themselves more with non-fat than with fat food, whereas the obesity group associated themselves to the same extent with fat and non-fat food. On the physical activity IAT, the IAT-effect of both groups did not differ from zero, respectively for the control group $t(38)=0.26$, ns, and for the obesity group $t(38)=0.61$, ns, indicating that both groups associated themselves to the same extent with physical activity and with rest (see Table 1).

\subsection{Self-reports}

The self-reported attitudes towards physical activity and food were obtained by averaging the item scores for each category of physical activity and for each category of food (see Table 2). To analyse the self-reported attitudes towards physical activity, a 2 (group: obese vs. normal-weight participants) $\times 2$ (word category: exercising vs. resting) ANOVA was carried out. No significant effects were found for group, word category and for the interaction effect of group and word category, respectively $F<0.49, F<0.04$, and $F<1.52$. Additional one sample $t$-tests, comparing the scores with the midpoint of the scale (10), showed both groups evaluated exercising $(M=11.18, \mathrm{SD}=3.47)$ and resting $(M=11.05, \mathrm{SD}=3.64)$ as mildly positive (respectively $t(76)=2.98, p<0.01, \delta=0.10$, and $t(78)=2.53, p<0.05, \delta=0.08)$.

Analysing the self-reported attitudes towards food, a 2 (group: obese vs. normal-weight participants) $\times 2$ (word category: non-fat food vs. fat food) ANOVA did neither reveal a significant main effect of group or word category, respectively $F<1.89$ and $F<1.02$, nor an interaction effect of group and word category, $F<1.36$. Additional one sample $t$-tests showed that both groups evaluated the fat food category mildly positive $(M=11.44$, $\mathrm{SD}=3.92), t(76)=3.22, p<0.01, \delta=0.12$, whereas the non-fat food category was appraised neutral $(M=10.73, \mathrm{SD}=3.96), t(76)=1.63$, ns. 
Table 2

Mean and standardized self-reported attitudes of the obesity and normal-weight group towards different kinds of physical activity and food trials, evaluated on a scale from 0 to 20

\begin{tabular}{|c|c|c|c|c|}
\hline & \multicolumn{2}{|c|}{ Obesity } & \multicolumn{2}{|c|}{ Normal-weight } \\
\hline & $M$ & $\mathrm{SD}$ & $M$ & $\mathrm{SD}$ \\
\hline \multicolumn{5}{|c|}{ Physical activity } \\
\hline Exercising & 11.73 & 3.44 & 10.61 & 3.45 \\
\hline Resting & 10.87 & 3.88 & 11.24 & 3.41 \\
\hline \multicolumn{5}{|l|}{ Food } \\
\hline Non-fat & 11.54 & 4.14 & 9.95 & 3.67 \\
\hline Fat & 11.43 & 4.01 & 11.44 & 3.87 \\
\hline
\end{tabular}

\section{Discussion}

The present study was designed to investigate whether differences exist in the implicit identification with and in the explicit attitudes towards food and physical activity in youngsters with and without obesity. On the implicit level, it was expected that children with obesity would associate themselves more with sedentariness and fat food than with exercising and non-fat food. On the explicit level, it was hypothesized that both groups would prefer exercising and non-fat food to inactivity and fat food in accordance with health-based societal norms.

The results revealed that youngsters with and without obesity had similar explicit attitudes towards both physical activity and food: both groups were neutral towards nonfat food and mildly positive towards sedentariness, exercising and fat food. The finding that there were no differences between youngsters with and without obesity is in line with previous research (Craeynest et al., 2005; Roefs \& Jansen, 2002) and could be due to the mentioned possible shortcomings of explicit measures (see also Schwarz, 1999; Schwarz \& Oyserman, 2001). However, the finding that not only the children with obesity but also the lean children reported they like sedentariness and fat food is remarkable, as it is not in line with our societal desirability hypothesis. It is possible that children are less sensitive for societal views than we had expected, or that their fat food preference reflects the evolutionary benefit of fat foods (Birch, 1992).

Counter to our expectations, we did not find that youngsters with obesity implicitly identified themselves more with fat food than with non-fat food. We also did not observe that youngsters with obesity implicitly identified themselves more with sedentariness than with exercising. In line with our former study (Craeynest et al., 2005), we did not find any effect for physical activity. Possibly, preferences towards sedentariness and exercising are highly context dependent (e.g., social context, weather,...) and could therefore not easily be assessed without referring to a particular context.

The IAT did reveal an intriguing effect for food. Youngsters without obesity identified themselves more strongly with non-fat food than with fat food. Youngsters with obesity did not show an effect. The results suggested that they identify themselves to the same extent with fat and non-fat food. This pattern of results evokes several considerations. 
A first reflection is that implicit identification with fat food seems to differentiate better between obese and non-obese persons than implicit attitudes towards fat food (e.g., Roefs \& Jansen, 2002). Similar to the findings of Swanson et al. (2001) (Experiments 2 and 3), stigmatised behaviour targets combined with the labels 'self versus other' in an identification IAT, seem to evoke less societal views than the combination with the normative labels 'positive versus negative' in a traditional IAT.

A second reflection concerns the finding that the difference between both groups is due to an identification with non-fat food in the lean children rather than to an identification with fat food in the obesity group. This suggests that it might be worthwhile to expand the focus in obesity research towards the underlying processes behind this lack of a stronger identification with non-fat food that seems to be characteristic for lean persons.

Third, it should be considered that the participants may have recoded the IAT task instructions and that they may have used strategies to facilitate the two separate discrimination tasks (De Houwer, 2002). Additionally, it has been demonstrated that in general, the IAT assesses implicit associations on the category level rather than on the exemplar level (De Houwer, 2001; but see Mitchell, Nosek, \& Banaji, 2003, Experiment 2). Therefore, because the labels we used in the food IAT were 'fat' versus 'non-fat', which were associated with the attribute concepts 'self' versus 'other', it is possible that the participants recoded the labels into 'fat people' versus 'lean people'. In that way, the implicit dissociation of fat in the control group could be attributed to an implicit anti-fat bias that people have (Teachman \& Brownell, 2001; Teachman, Gapinski, Brownell, Rawlins, \& Jeyaram, 2003). In other words, it is possible that the same results will be found if fat and non-fat food pictures are replaced by pictures of fat and lean people. The finding that the obesity group does not dissociate with fat, could be attributed to a negative selfesteem that is often found in children with obesity (see Friedlander, Larkin, Rosen, Palermo, \& Redline, 2003; Hesketh, Wake, \& Waters, 2004). Alternatively, it may be that the control children associated themselves more with non-fat because they are not fat. In contrast then, the obese children may be more ambiguous because of what they are (fat), and what they would like to be (not fat).

Within this context of food, it is also worthwhile to consider the theory of Berridge (1996). He differentiates two independent components in food reward that have separate neural substrates: liking (valence, attitude) and wanting (arousal, craving). As both processes can exist beyond conscious awareness, implicit measures may offer an accurate method to assess them. Until now, especially the liking component was investigated in obesity. However as mentioned in the introduction, attitude studies only revealed small effects (Craeynest et al., 2005) and even counterintuitive effects (Roefs \& Jansen, 2002). In contrast, Wiers et al. (2002) used an IAT in which alcohol vs. soda targets were associated with arousal and passive attributes. They found that heavy drinkers associated alcohol more strongly with arousal than did light drinkers, whereas both groups did not differ in their implicit attitudes towards alcohol. Wiers et al. (2002) interpreted these findings in terms of the incentive-sensitized theory (Robinson \& Berridge 1993), a model that resembles Berredige's (1996) theory of food reward. According to them, the results indicated that alcohol addiction is driven by a stronger wanting of alcohol, rather than by a greater liking of it. It may be interesting therefore, to investigate if children with obesity associate fat food more with arousal than with passive attributes. If the results then would reveal strong associations between fat food and arousal, it could imply that childhood obesity is especially associated with fat food craving. In line with this hypothesis, 
behavioural evidence already exists that obesity is linked with impulsivity (Nederkoorn, Braet, Van Eijs, Tanghe, \& Jansen, in press) and loosing control (Hakala, Rissanen, Koskenvuo, Kaprio, \& Rönnemaa, 1999).

There are some limitations in this study. First, as De Houwer (2002) noticed, the IAT can only provide a measure of the relative strength of associations, because at least two target concepts and two attribute concepts are needed. Therefore, it is impossible to know whether the children without obesity were slower on the combination self + fat/ other + non-fat because they associated themselves with non-fat food, or because they dissociated themselves with fat food. Second, in the context of self-esteem IATs, Karpinski (2004) pointed out that the nature of the mental representation of the self-attribute can change as a function of the mental representation of the other-attribute. This can affect both the overall IAT-scores as well as the self-associations. Likely, the same is true for the role of the other in a self-concept IAT. Third, Blair (2002) showed that implicit measures are sensitive to contextual manipulations. Therefore, the fact that the obesity group was tested in another setting than the control group may have affected the results. As Roefs et al. (2006, in press; Experiment 1) found that a temporary change in attention focus ('imagine you work in a restaurant' versus 'focus on health') determined whether palatable food was evaluated as tasty or unhealthy. Consequently, the effects of the obesity group could have been suppressed, because they were tested at the university, which is for them an unfamiliar setting. In contrast, the control children were tested in familiar settings where palatable fat food can be obtained (at school and for a minority at home). Finally, because the obesity group consisted of youngsters with severe obesity, these findings could not be generalized to the general population. It could be interesting to replicate this study in a non-clinical group of children with obesity (or overweight) and compare both results.

\section{Acknowledgements}

This research was supported by Grant B/03814/01 from Ghent University. The authors wish to thank all the children and the staff of the MPC Zeepreventorium in De Haan, Belgium, in especial Ann Tanghe for the practical organization. Also many thanks go to Lien Vandeweghe and Mieke Duthoo for their assistance in data collecting.

\section{Appendix. IAT stimuli}

\section{Targets}

Fat food pictures ${ }^{2}$ : hamburger, French fries, ice cream, crisps, chocolate, cake.

Non-fat food pictures (see footnote 2): yoghurt, vegetables, fruit, bread, cereals, soup.

Physical activity pictures (see footnote 2): basket, volley, tennis, running, biking, swimming.

Sedentary activity pictures (see footnote 2): watching TV, listening music, reading, sleeping, computer, GSM.

\footnotetext{
${ }^{2}$ Stimulus pictures can be obtained from the corresponding author.
} 


\section{Attributes}

'Self' words: ik (I), me (me), mij (me), mezelf (myself), mijn (my), m’n (my).

'Other' words: hij (he), zij (she), hem (him), haar (her), zijn (his), hun (their).

\section{References}

Berridge, K. C. (1996). Food reward: Brain substrates of wanting and liking. Neuroscience and Behavioral Reviews, 20, 1-25.

Birch, L. L. (1992). Children's preferences for high-fat foods. Nutrition Reviews, 50, 249-255.

Blair, I. (2002). The malleability of automatic stereotypes and prejudice. Personality and Social Psychology Review, 6, 242-261.

Brug, J., Lechner, L., \& De Vries, H. (1995). Psychosocial determinants of fruit and vegetable consumption. Appetite, 25, 285-295.

Cohen, J. (1988). Statistical power analysis for the behavioral sciences (2nd ed.). NJ: Lawrence Erlbaum.

Craeynest, M., Crombez, G., De Houwer, J., Deforche, B., Tanghe, A., \& De Bourdeaudhuij, I. (2005). Explicit and implicit attitudes toward food and physical activity in childhood obesity. Behaviour Research and Therapy, 43, 1111-1120.

De Clercq, A., Crombez, G., Buysse, A., \& Roeyers, H. (2003). A simple and sensitive method to measure timing accuracy. Behavior Research Methods, Instruments and Computers, 35, 109-115.

Deforche, B., De Bourdeaudhuij, I., Tanghe, A., Hills, A. P., \& De Bode, P. (2004). Changes in physical activity and psychosocial determinants of psychical activity in children and adolescents treated for obesity. Patient Education and Counseling, 55, 407-415.

De Houwer, J. (2001). A structural and process analysis of the Implicit Association Test. Journal of Experimental Social Psychology, 37, 443-451.

De Houwer, J. (2002). The IAT as a tool for studying dysfunctional associations in psychopathology: Strengths and limitations. Journal of Behavior Therapy and Experimental Psychiatry, 33, 115-133.

De Houwer, J. (2003). The Extrinsic Affective Simon Task. Experimental Psychology, 50, 77-85.

De Houwer, J., Crombez, G., Koster, E. H. W., \& De Beul, N. (2004). Implicit alcohol-related cognitions in a clinical sample of heavy drinkers. Journal of Behavior Therapy and Experimental Psychiatry, 35, 275-286.

Eriksson, J., Forsen, T., Tuomilehto, J., Osmond, C., \& Barker, D. (2001). Size at birth, childhood growth and obesity in adult life. International Journal of Obesity, 25, 735-740.

Fazio, R. H. (1990). Multiple processes by which attitudes guide behaviour: The MODE model as an integrative framework. Advances in Experimental Social Psychology, 23, 75-109.

Fazio, R. H. (2001). On the automatic activation of associated evaluations: An overview. Cognition and Emotion, $15,115-141$.

Fazio, R. H., \& Olson, M. A. (2003). Implicit measures in social cognition research: Their meaning and use. Annual Review of Psychology, 54, 297-327.

Friedlander, S. L., Larkin, E. K., Rosen, C. L., Palermo, T. M., \& Redline, S. (2003). Decreased quality of life associated with obesity in school-aged children. Archives of Pediatrics and Adolescent Medicine, 157, 1206-1211.

Greenwald, A. G., Banaji, M. R., Rudman, L. A., Farnham, S. D., Nosek, B. A., \& Mellot, D. S. (2002). A unified theory of implicit attitudes, stereotypes, self-esteem, and self-concept. Psychological Review, 109, 3-25.

Greenwald, A. G., McGhee, D. E., \& Schwartz, J. L. (1998). Measuring individual differences in implicit cognition: The Implicit Association Test. Journal of Personality and Social Psychology, 74, 1464-1480.

Greenwald, A. G., Nosek, B. A., \& Banaji, M. R. (2003). Understanding and using the Implicit Association Test: An improved scoring algorithm. Journal of Personality and Social Psychology, 85, 197-216.

Hakala, P., Rissanen, A., Koskenvuo, M., Kaprio, J., \& Rönnemaa, T. (1999). Environmental factors in the development of obesity in identical twins. International Journal of Obesity, 23, 746-753.

Hesketh, K., Wake, M., \& Waters, E. (2004). Body mass index and parent-reported self-esteem in elementary school children: Evidence for a causal relationship. International Journal of Obesity, 28, 1233-1237.

James, P. T., Leach, R., Kalamara, E., \& Shayeghi, M. (2001). The worldwide obesity epidemic. Obesity Research, 9, 228S-233S.

Karpinski, A. (2004). Measuring self-esteem using the Implicit Association Test: The role of the other. Personality and Social Psychology, 30, 22-34. 
Karpinski, A., \& Hilton, J. L. (2001). Attitudes and the Implicit Association Test. Journal of Personality and Social Psychology, 81, 774-788.

McGloin, A. F., Livingstone, M. B. E., Greene, L. C., Webb, S. E., Gibson, J. M. A., Jebb, S. A., et al. (2002). Energy and fat intake in obese children and lean children at varying risk of obesity. International Journal of Obesity, 26, 200-207.

Mitchell, J. P., Nosek, B. A., \& Banaji, M. R. (2003). Contextual variations in implicit evaluation. Journal of Experimental Psychology: General, 132, 455-469.

Morgan, C. M., Tanofsky-Kraff, M., Wilfley, D. E., \& Yanovski, J. A. (2002). Childhood obesity. Child and Adolescent Psychiatric Clinics of North America, 11, $257+$.

Nederkoorn, C., Braet, C., Van Eijs, Y., Tanghe, A., \& Jansen, A. (in press). Why obese children can not resist food: The role of impulsivity. Eating Behaviors.

Nicklas, T. A., Yang, S.-J., Baranowski, T., Zakeri, I., \& Berenson, G. (2003). Eating patterns and obesity in children. The Bogalusa Heart Study. American Journal of Preventive Medecine, 25, 9-16.

Nosek, B. A., Banaji, M. R., \& Greenwald, A. G. (2002). Math = male, me = female, therefore math not equal me. Journal of Personality and Social Psychology, 83, 44-59.

Perl, M. A., Mandic, M. L., Primorac, L., Klapec, T., \& Perl, A. (1998). Adolescent acceptance of different foods by obesity status and by sex. Physiology and Behaviour, 65, 241-245.

Popkin, B. M. (1998). Worldwide trends in obesity. Journal of Nutrition Biochemistry, 9, 487-488.

Robinson, T. E., \& Berridge, K. C. (1993). The neural basis of drug craving: An incentive-sensitization theory of addiction. Brain Research Reviews, 18, 247-291.

Roefs, A., \& Jansen, A. (2002). Implicit and explicit attitudes toward high-fat foods in obesity. Journal of Abnormal Psychology, 111, 517-521.

Roefs, A., Quaedackers, L., Werrij, M. Q., Wolters, G., Havermans, R., Nederkoorn, C., et al. (2006). The environment influences whether high-fat foods are associated with palatable or with unhealthy. Behaviour Research and Therapy, 44, 715-736.

Schwarz, N. (1999). Self-reports. How the questions shape the answers. American Psychologist, 54, 93-105.

Schwarz, N., \& Oyserman, D. (2001). Asking questions about behaviour: Cognition, communication, and questionnaire construction. American Journal of Evaluation, 22, 127-160.

Smith, R. A., \& Biddle, S. J. H. (1999). Attitudes and exercise adherence: Test of the Theories of Reasoned Action and Planned Behaviour. Journal of Sport Sciences, 17, 269-281.

Swanson, J. E., Rudman, L. A., \& Greenwald, A. G. (2001). Using the Implicit Association Test to investigate attitude-behaviour consistency for stigmatised behaviour. Cognition and Emotion, 15, 207-230.

Teachman, B. A., \& Brownell, K. D. (2001). Implicit anti-fat bias among health professionals: Is anyone immune? International Journal of Obesity, 25, 1525-1531.

Teachman, B. A., Gapinski, K. D., Brownell, K. D., Rawlins, M., \& Jeyaram, S. (2003). Demonstrations of implicit anti-fat bias: The impact of providing causal information and evoking empathy. Health Psychology, $22,68-78$.

Togashi, K., Masuda, H., Rankinen, T., Tanaka, S., Bouchard, C., \& Kamiya, H. (2002). A 12-year follow-up study of treated obese children in Japan. International Journal of Obesity, 26, 770-777.

Trost, S. G., Sirard, J. R., Dowda, M., Pfeiffer, K. A., \& Pate, R. R. (2003). Physical activity in overweight and nonoverweight preschool children. International Journal of Obesity, 27, 834-839.

Valverde, M. A., Patin, R. V., Oliveira, F. L. C., Lopez, F. A., \& Vitolo, M. R. (1998). Outcomes of obese children and adolescents enrolled in a multidisciplinary health program. International Journal of Obesity, 22, 513-519.

Wiers, R. W., van Woerden, N., Smulders, F. T. Y., \& de Jong, P. J. (2002). Implicit and explicit alcohol-related cognitions in heavy and light drinkers. Journal of Abnormal Psychology, 111, 648-658. 